\title{
Grade Predictors in a SECONdARy SuMmer CourSe OFFERING: AN INVESTIGATION OF PRIOR FAILURES AND EMPLOYMENT
}

\author{
Julie Vale and Ryan Clemmer \\ University of Guelph \\ jvale@uoguelph.ca, rclemmer@uoguelph.ca
}

\begin{abstract}
A second year electrical circuits course at the author's home institution was historically delivered in the winter term to one section of approximately 400 students. The department observed that approximately 70 100 students were losing a year of school due to the combined high fail rates and single offerings of this course and its prerequisite. To allow these students to remain on track in their programs, additional offerings of both courses were created. The secondary offering of the circuits course was offered in the summer term.

This paper presents a statistical analysis of data obtained over two years of the summer offering of the circuits course. After correcting for GPA and attendance, prior failures in both courses and having a job (co-op or otherwise) are shown to have no statistical significance.

These results indicate that concerns around employment workload and sufficient time to study appear to be unfounded and that the fact that a student has failed in the past does not predict their future grades.

This preliminary work is part of a larger research project investigating the impact of an online, blended delivery approach on attendance, student perception of learning, and impact on grades.
\end{abstract}

Keywords: Grades, secondary offering, co-op, work hours, prior failures.

\section{INTRODUCTION}

A second-year circuits course at the researcher's home institution experienced high failure rates. The prerequisite for this course also experienced high failure rates. As a result, a secondary summer offering of the circuits course was created. As this was the first such course offered by the department, a large quality assurance survey was conducted to assess the impacts of various effects on student learning and grades.

This paper presents the preliminary analysis of two years of data - the first offering (S1) and the second offering (S2). The analysis includes GPA, Attendance, Jobs, Co-op, and prior failures in this course and the prerequisite. This study is part of a larger research project with additional analysis to be published in future manuscripts.

Assessing student learning and predicting student success is highly complex. Students' innate abilities, motivation, and habits are all factors that affect their performance which makes separating these specific influences on student success difficult [11].

In the literature, there are two aspects that are either inconclusive or under reported. The effect of employment on student learning is the subject of several studies with mixed conclusions $[4,9,11]$. For some students, working is a meaningful way to build skills and experience necessary for their academic success, whereas other students may find that the additional time spent working takes away their time from studying [5].

Another aspect of predicting student performance that seems to be lacking in the literature is the effect of prior failures in prerequisite courses on student grades in followon courses. There are a number of studies that look to improve retention rates in programs to reduce attrition rates throughout a program of study, but there seems to be a lack of research relating specifically to the influence prior failures have on future success $[1,6]$. While failed courses may lead to greater attrition, and remedial offerings of courses are offered to improve learning, it is unclear if students who fail courses will be at a disadvantage to their peers in follow-on courses in their program.

To investigate the influence of employment and prior failures further, the following research questions are the subject of this study:

a) Do jobs impact student performance in a secondary, summer course offering?

i) Does having a job at all impact performance?

ii) Does having a co-op (vs non-coop) job impact performance?

b) Do prior failures in a course or its prerequisite impact student performance in a secondary offering of that course? 


\subsection{Outline}

This paper is organized as follows: we begin with methods and materials, where we outline relevant aspects of the course, the participant pool, the instruments, and the statistical tools. We then present our statistical analysis of correlations between Grades and GPA, attendance, jobs and Coop, and prior failures. We conclude with a discussion of the results and relevant conclusions.

\section{METHODS AND MATERIALS}

\subsection{The course}

The course is a second-year electric circuits course core to all engineering students in the authors' institution. The course has three hours of lectures/week and two hours/week of time that alternated between problem solving tutorials and hands-on lab time. Tutorials and labs were delivered by teaching assistants and lectures were delivered by a faculty member. The course instructor is one of the authors.

This research focuses on secondary (summer) offerings of this course. These secondary offerings were delivered by the same instructor, in the same format, and with the same set of lecture notes as the regular offerings. Any student who have successfully completed the appropriate prerequisites could access this course.

The instructor delivered the lectures by scribing handwritten notes on a Microsoft Surface which were projected onto large screens at the front of the class. In addition to the live handwritten notes, all students had access to a set of incomplete textbook-style course notes that contained strategic blank spaces for students to fill in during lectures.

Tutorials were ungraded and provided students with structured mini-lessons on the previous two week's material followed by structured, peer-assisted problemsolving sessions. Labs were performed and assessed during evening sessions in groups of two and consisted of hands-on experiential learning opportunities where students built and measured circuits and compared their results to theoretical predictions based on the material that they learned in lecture. Alternate lab schedules (e.g., intensive Saturday sections) were available for students who were attending from very long distances.

The assessment breakdown of the course was (nominally)

- $\quad$ Lab (group): $15 \%$

- $\quad$ Midterm (individual): $30 \%$

- $\quad$ Final (individual): $55 \%$

In all cases, students were required to pass the combination of the midterm and final to pass the course.

\subsubsection{Online components (secondary offerings only)}

Many students who wanted to access the summer offerings were living away from the university that term.
To address the needs of these students, the summer offerings added the use of Adobe Connect version 9 (Adobe Systems, San Francisco, California) to live-stream the lectures, including both the instructor's voice and the instructor's hand-written notes (scribed using Microsoft Journal (Microsoft, Redmond, Washington)) on a Surface Pro 2 (Microsoft, Redmond, Washington). Video was not included in the feed.

A major concern during summer course planning was the ability for remote access students to engage with the lectures, so the 'Chat Pod' feature in Adobe Connect was enabled, allowing remote users to participate synchronously in the lectures by typing text in an online chat box. Students (both remote and physical) could type questions or comments, and the instructor would then acknowledge and verbally respond. In the classroom, the chat and handwritten notes were simultaneously projected onto the screen at the front of the classroom so that participants physically present in the room could see the chat content without being logged in.

\subsection{Participants}

The participant pool was all registered students for the S1 $(n=74)$ and S2 (n=47) offerings. From those pools, 42 students in S1 and 15 students in S2 provided consent to participate in this study. Some participants were removed from the study for one of two reasons: 1) participants did not fully complete the survey and 2) participants did not write one of the two exams.

The overall course averages were $61.5 \%$ (S1) and $57.9 \%$ (S2), while the overall course average of participants was $63.6 \%$ (S1) and $63.7 \%$ (S2).

Because this was a secondary offering of the course, a key demographic in this study was the (self-reported) number of times that participants failed either this course or its prerequisite (see Table 1 ).

Table 1: Prior failures by course

\begin{tabular}{c|cc} 
& Yes & No \\
\hline Failed prerequisite & 31 & 26 \\
Failed circuits course & 32 & 25 \\
Failed both courses & 15 & 42 \\
Failed neither course & 9 & 48
\end{tabular}

Participants were recruited via an in-class announcement and an email inviting them to participate in the study. The email and associated on-line survey were sent to students in the last two weeks of class. Informed consent was administered via the first question in the online survey.

\subsection{Survey}

Participants were asked to complete a Research Ethics Board (REB) approved survey. This survey was initially 
created by the researchers as a quality assurance tool to assess the novel delivery of this first ever summer course offering. As such, many of these questions were asked as part of the program and instructor's continual improvement efforts and are not relevant to this study; relevant questions are included in the appendix.

The online survey used a combination of Likert-style questions, open-ended response boxes, and specific numeric questions. The survey assessed multiple aspects of the course delivery and student experience including

- Attendance and workload (22 questions)

- Employment and commuting (15 questions)

- $\quad$ Course delivery and engagement (23 questions)

- Demographics (7 questions related to GPA, failed courses, program of study, etc.)

The survey was re-administered the following year. In all cases, student responses were tied to their final course grade.

A potential limitation of this study is the reliance on self-reported student data; however, as long as survey questions are clear, refer to recent activities, the respondents think the questions are important, and answering the questions does not violate the privacy of the respondent, then the results are likely valid [7,8]. All of these conditions are true in our study, therefore, our selfreported data (including GPA and attendance) are likely valid.

\subsection{Quantitative Analysis}

Analysis of variance procedures (ANOVA), t-tests, and Multiple Linear Regressions (MLR) were performed $(\mathrm{p} \leq 0.05)$ on the dependent variable Grade (\%). The independent variables were all self-reported and included

- GPA

- Percentage attendance

- Whether or not the participant had a job and if that job was a co-op position

- Existence of prior failures in this course and the prerequisite course

Data for the independent variables were obtained from the completed questionnaires. All statistical analyses were performed using $\mathrm{R}$, version 3.5.1.

\section{RESULTS}

From related research, both GPA and attendance are known predictors of grade outcomes [10], so our analysis began by incorporating these two factors. We then follow with an analysis of the impact of jobs (including co-op vs non-co-op) and then an analysis of the impact of prior failures.

\subsection{Accounting for GPA and Attendance}

A linear regression was performed correlating Grades to self-reported GPA, yielding

$$
\text { Grades }=-9.63+1.09 * \mathrm{GPA} \text {, }
$$

with $\mathrm{R}^{2}=0.124$ (see Table 2 and Figure 1).

\section{Table 2:ANOVA of Grade vs Self-reported GPA}

\begin{tabular}{l|cccccc} 
& $\begin{array}{c}\text { Degrees } \\
\text { of } \\
\text { Freedom }\end{array}$ & $\begin{array}{c}\text { Sum of } \\
\text { squares }\end{array}$ & $\begin{array}{c}\text { Mean } \\
\text { square }\end{array}$ & Fvalue & $p$ \\
\hline GPA & 1 & 1413 & 1413 & 7.79 & 0.0072 \\
Residuals & 55 & 9976 & 181 & &
\end{tabular}

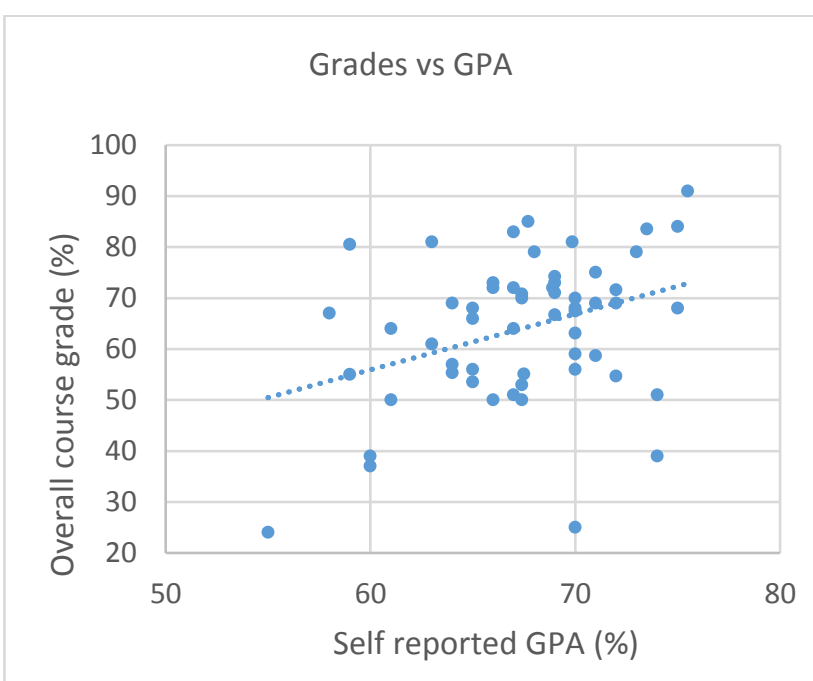

Figure 1: Overall course grades against Self-reported GPA $(p=0.0072)$

To assess whether attendance impacted student grades, students were asked to self-report overall attendance on a four-point scale $(\langle 25 \% ; 25-50 \% ; 50-75 \%\rangle 75 \%$,$) . Given$ the low number of participants in the first three bins $(<20 \% ; 25-50 \% ; 50-75 \%)$, we collected those bins into one category (Attendance $=0, \mathrm{n}=17$ ) and the $>75 \%$ bin into another (Attendance=1, $n=40$ ). With this setup, we performed a Multiple Linear Regression (MLR) yielding

Grade $=0.97+0.80 * \mathrm{GPA}+12.72 *$ Attendance, with $\mathrm{R}^{2}=0.285$ (see Figure 2 and Table 3 ). ${ }^{1}$ This is an improvement of 0.161 over the model with GPA alone, indicating that attendance is a stronger predictor of grades than GPA. In particular, attending more than $75 \%$ of lectures yields grades that are (on average) $12.78 \%$ higher for participants with the same GPA. Furthermore, the $95 \%$ confidence interval for the attendance effect is roughly $5.38 \%-20 \%$. This is consistent with prior studies

\footnotetext{
1 The interaction term between Attendance and GPA yielded negligible improvement in the model and was not significant, and hence was not included.
} 
indicating that attendance has a significant impact on grades when students miss more than $50 \%$ of classes $[2,10]$.

Table 3: ANOVA of Grade vs Self-reported GPA and Attendance, parallel model

\begin{tabular}{l|cccccc} 
& $\begin{array}{c}\text { Degrees } \\
\text { of } \\
\text { Freedom }\end{array}$ & $\begin{array}{c}\text { Sum of } \\
\text { squares }\end{array}$ & $\begin{array}{c}\text { Mean } \\
\text { square }\end{array}$ & Fvalue & $p$ \\
\hline GPA & 1 & 1413 & 1413 & 9.37 & 0.0034 \\
Attendance & 1 & 1832 & 1832 & 12.15 & 0.0010 \\
Residuals & 54 & 8145 & 151 & &
\end{tabular}

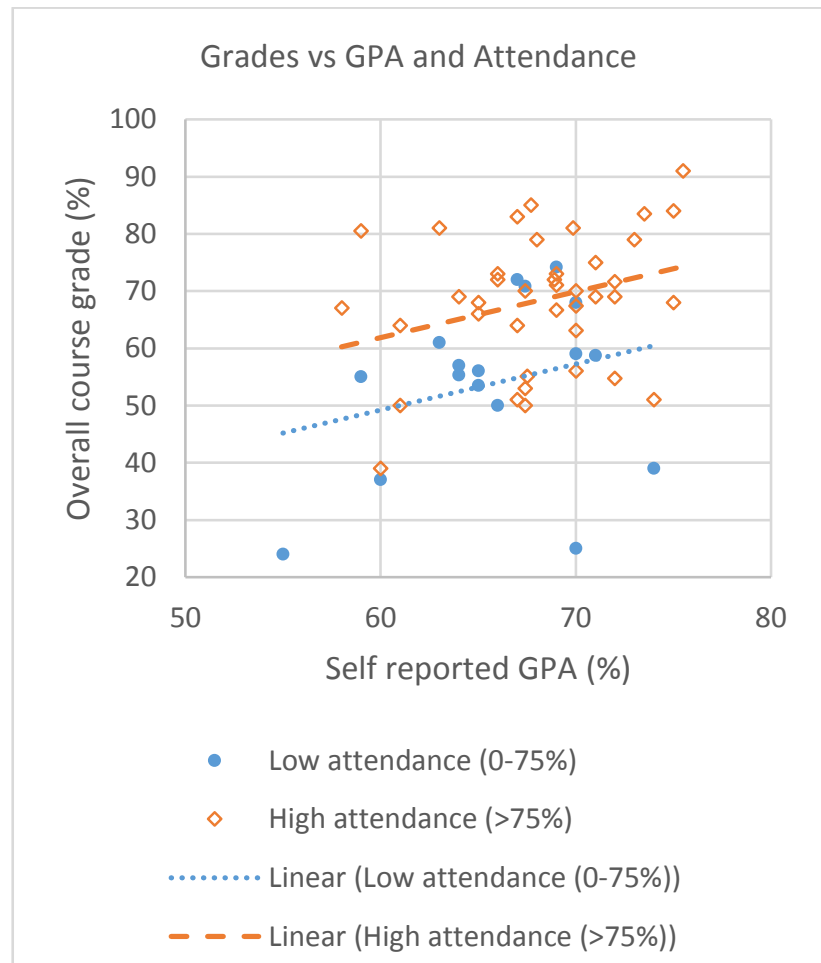

Figure 2: Overall course grades against Self-reported GPA and Attendance, parallel model

\subsection{Effect of Co-op and Work}

We began by investigating the effect of having a job vs not having a job. The contingency table (Table 4) indicates there may be a strong relationship between those participants who do not have a job and attendance. A Chi square test yields $\mathrm{p}=0.260$, indicating that there is no detectable relationship, but the samples are small and therefore the approximations may be incorrect.

Table 4: Contingency table comparing Jobs to Attendance

\begin{tabular}{l|cc} 
& Low attendance & High attendance \\
\hline No job & 2 & 12 \\
Yes job & 15 & 28
\end{tabular}

Since only two participants reported having no job and having low attendance, we risk overfitting, so we analyzed only those students in the high attending group $(n=40)$. A linear regression of Grades vs GPA was performed on this subset of the data, yielding

$$
\text { Grades }=19.06+0.72 * \mathrm{GPA} \text {, }
$$

with $\mathrm{R}^{2}=0.0745$ (see Table 5). Note that GPA is a much weaker predictor of grades for this group of participants and is no longer significant.

Table 5: ANOVA of Grade vs Self-reported GPA for high attending participants

\begin{tabular}{l|ccccc} 
& $\begin{array}{c}\text { Degrees } \\
\text { of } \\
\text { Freedom }\end{array}$ & $\begin{array}{c}\text { Sum of } \\
\text { squares }\end{array}$ & $\begin{array}{c}\text { Mean } \\
\text { square }\end{array}$ & Fvalue & $p$ \\
\hline GPA & 1 & 393 & 393 & 3.06 & 0.088 \\
Residuals & 38 & 4883 & 129 & &
\end{tabular}

A simple two-sided t-test comparing the grades of participants in the Job (Mean=69.5, $\mathrm{SD}=10.4, \mathrm{n}=28$ ) vs No Job (Mean=65.7, SD=14.19, $\mathrm{n}=12$ ) categories yields $\mathrm{p}=0.4115$. The difference in means is quite small (less than half a letter grade); indeed, a power analysis (power $=0.8$ ) revealed that, if a significant difference between the means of these two groups does exist, 256 more participants (296 total) would need to be added to the study to observe that difference.

We then excluded those participants who did not have a job and proceeded to investigate the impact of Co-op. The MLR of Grades against Attendance and GPA for this subset ( $n=43$ ) yields significant results and $R^{2}=0.304$, but the addition of Co-op vs Non-Co-op only increases the fit to $\mathrm{R}^{2}=0.326$ and is not significant (see Table 6 ).

Table 6: ANOVA of Grade vs Self-reported GPA, Attendance, and Co-op vs Non-co-op for participants with jobs

\begin{tabular}{l|ccccc} 
& $\begin{array}{c}\text { Degrees } \\
\text { of } \\
\text { Freedom }\end{array}$ & $\begin{array}{c}\text { Sum of } \\
\text { squares }\end{array}$ & $\begin{array}{c}\text { Mean } \\
\text { square }\end{array}$ & Fvalue & $p$ \\
\hline GPA & 1 & 1354 & 1354 & 9.11 & 0.0045 \\
Attendance & 1 & 1172 & 1172 & 7.89 & 0.0077 \\
Co-op & 1 & 15 & 15 & 0.10 & 0.7532 \\
Co-op:GPA & 1 & 167 & 167 & 1.10 & 0.3006 \\
Residuals & 38 & 5611 & 151 & &
\end{tabular}

\subsection{Effect of Prior Failures}

Including attendance in the analysis of prior failures proved to be difficult due to small sample sizes and the potential for overfitting (e.g., only one participant failed neither course AND had low attendance; similarly, only five participants reported failing the prerequisite AND having low attendance-see Table 7 and Table 8). Chi- 
squared tests on the failures in the prerequisite, failures in this course, and combined failures yield $p=0.19, p=1$, and $\mathrm{p}=0.32$ respectively (in this last case, sample sizes were small enough that the approximations may not be correct); therefore, attendance is not considered in this analysis.

Table 7: Combined contingency table for Attendance vs prior failures by the prerequisite (prereq) and circuits courses

\begin{tabular}{l|cc|cc} 
& $\begin{array}{c}\text { Failed } \\
\text { prereq }\end{array}$ & $\begin{array}{c}\text { Did not } \\
\text { fail prereq }\end{array}$ & $\begin{array}{c}\text { Failed } \\
\text { circuits }\end{array}$ & $\begin{array}{c}\text { Did not } \\
\text { fail circuits }\end{array}$ \\
\hline $\begin{array}{l}\text { Low } \\
\text { attendance }\end{array}$ & 12 & 5 & 10 & 7 \\
$\begin{array}{l}\text { High } \\
\text { attendance }\end{array}$ & 19 & 21 & 22 & 18
\end{tabular}

Table 8: Contingency table for Attendance vs combined prior failures for the prerequisite and circuits courses

\begin{tabular}{l|ccc} 
& Failed neither & Failed one & Failed both \\
\hline $\begin{array}{l}\text { Low } \\
\text { attendance }\end{array}$ & 1 & 10 & 6 \\
$\begin{array}{l}\text { High } \\
\text { attendance }\end{array}$ & 8 & 23 & 9
\end{tabular}

MLRs comparing Grades to GPA and prior failures in the prerequisite course and to prior failures in the circuits course yielded no significance (Table 9, Table 10, Figure 3, and Figure 4).

Finally, we also ran an MLR on the combined fail count (i.e., no prior failures, failed one or the other, failed both), which also yielded no significance (Table 11).

Table 9: ANOVA of Grades vs self-reported GPA and prior failures in the prerequisite (prereq) course

\begin{tabular}{l|cccccc} 
& $\begin{array}{c}\text { Degrees } \\
\text { of } \\
\text { Freedom }\end{array}$ & $\begin{array}{c}\text { Sum of } \\
\text { squares }\end{array}$ & $\begin{array}{c}\text { Mean } \\
\text { square }\end{array}$ & Fvalue & $p$ \\
\hline $\begin{array}{l}\text { GPA } \\
\begin{array}{l}\text { Failed } \\
\text { prereq }\end{array}\end{array}$ & 1 & 1413 & 1413 & 7.65 & 0.0078 \\
$\begin{array}{l}\text { Failed } \\
\text { prereq:GPA } \\
\text { Residuals }\end{array}$ & 1 & 1 & 1 & 0.01 & 0.9434 \\
& 53 & 9787 & 185 & & &
\end{tabular}

Table 10: ANOVA of Grades vs Self-reported GPA and prior failures in circuits

\begin{tabular}{l|cccccc} 
& $\begin{array}{c}\text { Degrees } \\
\text { of } \\
\text { Freedom }\end{array}$ & $\begin{array}{c}\text { Sum of } \\
\text { squares }\end{array}$ & $\begin{array}{c}\text { Mean } \\
\text { square }\end{array}$ & Fvalue & $P$ \\
\hline GPA & 1 & 1413 & 1413 & 7.88 & 0.0070 \\
$\begin{array}{l}\text { Failed } \\
\text { circuits }\end{array}$ & 1 & 141 & 141 & 0.78 & 0.3800 \\
$\begin{array}{l}\text { Failed } \\
\text { circuits:GPA }\end{array}$ & 1 & 335 & 335 & 1.87 & 0.1771 \\
Residuals & 53 & 9501 & 179 & & \\
& & & & &
\end{tabular}

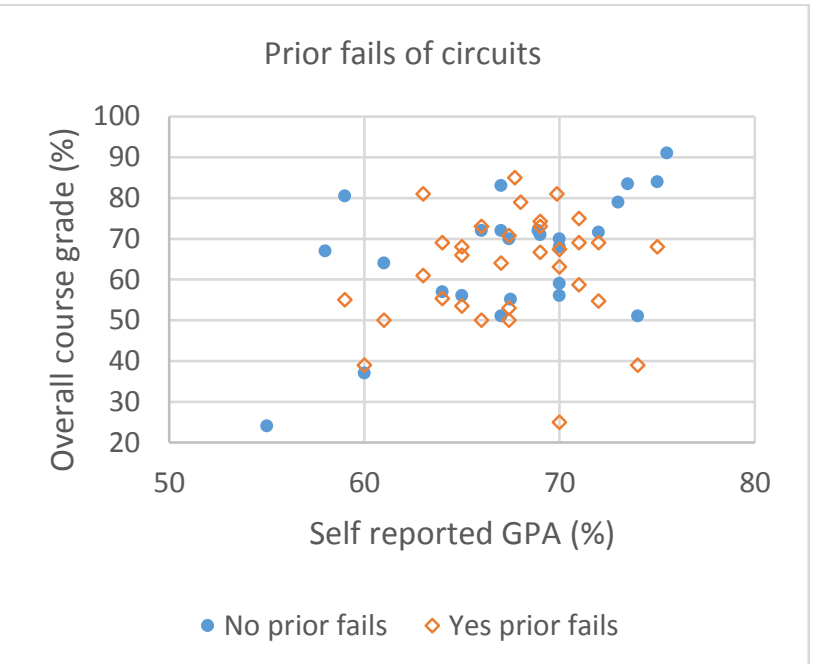

Figure 3: Grades vs GPA separated by prior failures (yes/no) of circuits

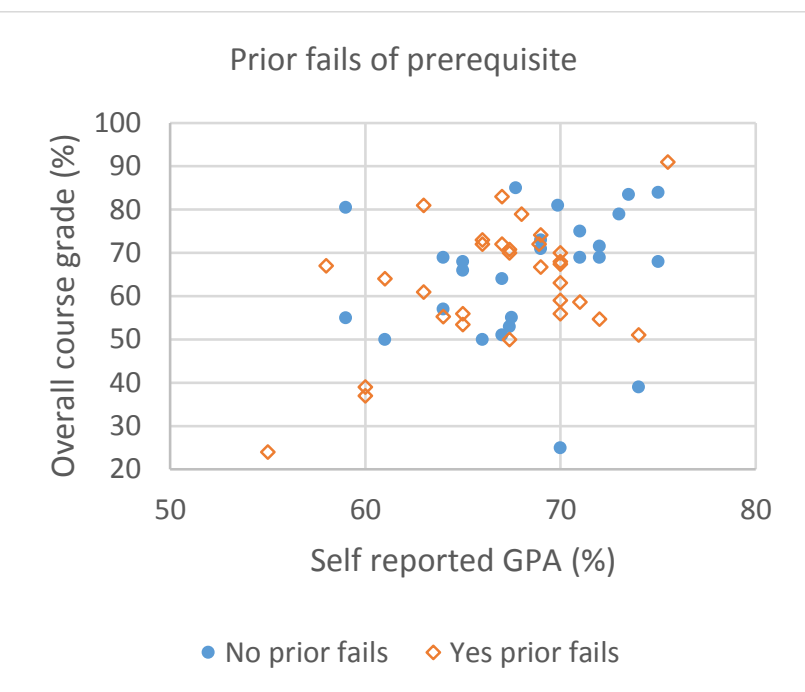

Figure 4: Grades vs GPA separated by prior failures (yes/no) of prerequisite 
Table 11: ANOVA of Grades vs Self-reported GPA and count of prior failures

\begin{tabular}{l|ccccc} 
& $\begin{array}{c}\text { Degrees } \\
\text { of } \\
\text { Freedom }\end{array}$ & $\begin{array}{c}\text { Sum of } \\
\text { squares }\end{array}$ & $\begin{array}{c}\text { Mean } \\
\text { square }\end{array}$ & Fvalue & $p$ \\
\hline GPA & 1 & 1413 & 1413 & 7.41 & 0.0089 \\
Fail count & 2 & 240 & 120 & 0.63 & 0.5366 \\
$\begin{array}{l}\text { Fail } \\
\text { count:GPA }\end{array}$ & 2 & 11 & 5.3 & 0.03 & 0.9726 \\
Residuals & 51 & 9727 & 191 & &
\end{tabular}

\section{DISCUSSION}

Our results clearly show that attendance is the single strongest predictor of grades, followed by GPA. Both of these results are consistent with the literature [3]. Indeed, our analysis of attendance indicates that simply choosing to attend $75 \%$ or more of classes can lead to an increase in grade of at least $5 \%$, and possibly as high as $20 \%$. GPA and attendance are the only significant predictors of course grades in this study.

\subsection{Do jobs have an effect?}

Our analysis of participants with Co-op jobs vs non-Coop jobs indicates that there is no statistical significanceindeed, the relationship is so weak that we conclude that increasing the sample size until an effect was detected would yield such a small effect that it would be negligible, especially when compared to the effect of attendance.

Our analysis of Jobs is less conclusive. Increasing the sample size would help to improve our results and possibly yield a non-negligible effect, but the contingency tables indicate that there may be a correlation between those students who have jobs and the ability to attend class. Indeed, if the number of samples were increased, any effect of jobs on grades may actually be due to the fact that having a job may make it less likely for students to attend class. While our results do not address causality, the literature [5] supports the argument that having a job may reduce the number of hours that a student can devote to classes.

An important point to consider is the cognitive load the students are experiencing during the summer secondary offering of the course. With only one course, students may be better able to balance the demands of a job and academics. In a typical semester, where students are taking several courses, the additional time demands of a job my impact academic performance to a greater extent. The work in this study, however, offers further support to the time trade-off hypothesis, suggesting that students must balance academics with other priorities such as employment and other organizational activities [5,12].

\subsection{Do prior failures have an effect?}

Given that these were secondary course offerings, most students in the study (88\%) had failed either this course or its prerequisite. Interestingly, there is no statistical significance relating these failures to the student's overall grade, even after correcting for GPA, nor is there any relationship between prior failures and participant's tendency to attend class. Indeed, when we plot these results, there is no clear pattern other than the correlation between Grades and GPA (see Figure 3 and Figure 4); given the variance in the data and the small effect size, we hypothesize that, even if we did increase the sample size until we obtained significance, the confidence interval would be so small as to be negligible.

Our prerequisite failure results are particularly compelling (with $\mathrm{p}$ very close to 1 ). These results seem to imply that students who pass the prerequisite are all on the same 'playing field', irrespective of how many attempts it took to achieve that passing grade. This is of particular relevance to institutions that include all previous failures in students' GPA calculation - we argue that such institutions should reconsider these policies, since there is no evidence that those prior grades have any impact on students' current performance.

\section{CONCULUSIONS AND FUTURE WORK}

While attendance and GPA remain statistically significant predictors of grades, the other factors studied here (jobs, Co-op, and previous failures) are not. Furthermore, we hypothesize that, even if sample sizes were increased, attendance and GPA effects would overshadow any observed effect of prior failures and jobs. We conclude that taking steps to make secondary offerings of classes accessible overshadows any other concerns that may arise surrounding secondary summer offerings of courses. Indeed, we are currently exploring this issue further and are investigating factors that contribute to student perceptions of positive and negative impacts on learning (including remote vs live attendance).

A more targeted study on the influence of prior failures on performance in follow-on courses is needed to better understand this effect. While prior failures do not seem to influence student performance in the secondary offering of this course, there may be other factors that become evident when examining student performance in a more traditional offering.

\section{Acknowledgements}

We would like to thank Dr. Gary Umphrey, Department of Math and Stats, University of Guelph, for sharing his statistical expertise. 


\section{References}

[1] M. Besterfield-Sacre, C.J. Atman, and L.J. Shuman, "Characteristics of freshman engineering students: Models for determining student attrition in engineering," Journal of Engineering Education, pp. 139-149, April 1997.

[2] J.J. Bethune, "Attendance, grades, and learning in microeconomic principles class," Journal of Economics and Economic Education Research, vol. 11, no. 1, pp. 53-64, 2010

[3] M. Crede, S.G. Roch, and U.M. Kieszczynka, "Class attendance in college: A meta-analytic review of the relationship of class attendance with grades and student characteristics," Review of Educational Research, vol. 80, no. 2, pp. 272-295, June 2010.

[4] P.M. Gleason, "College student employment, academic progress, and postcollege labor market success," Journal of Student Financial Aid, vol. 23, no. 2, Spring 2003.

[5] K.M. Greene and J.L. Maggs, "Revisiting the time trade-off hypothesis: Work, organized activities, and academics during college," Journal of Youth Adolescence, vol. 44, pp. 1623-1637, 2015.

[6] J.E. Hoyt, "Remedial education and student attrition," Community College Review, vol. 27, no. 2, pp. 51-72, 1999.

[7] G.D. Kuh, "The National Survey of Student Engagement: Conceptual framework and overview of pyschometric properties," Framework \& Psychometric Properties, pp. 1-26, 2002.

[8] R. Owston, D. Lupshenyuk and H. Wideman, "Lecture capture in large undergraduate classes: Student perceptions and academic performance,"
Internet and Higher Education, vol. 14, pp. 262-268, 2011.

[9] S.C. Riggert, M. Boyle, J.M. Petrosko, D. Ash, and C. Rude-Parkins, "Student employment and higher education: Empiricism and contradiction," Review of Educational Research, Vol. 76, No. 1, pp. 63-92, Spring 2006.

[10]L. Stanca, "The effects of attendance on academic performance: Panel data evidence for introductory microeconomics," Research in Economic Education, pp.251-265, Summer 2006

[11]R. Stinebrickner and T.R. Stinebrickner, "Working during school and academic performance," Journal of Labor Economics, vol. 21, no. 2, pp. 473-491, 2003.

[12] S. Svanum and S. Bigatti, "The influences of course effort and outside activities on grades in a college course," Journal of College Student Development, pp. 564-576, 2006.

\section{APPENDIX A: RELEVANT SURVEY QUESTIONS}

What percentage of classes did you attend? 0-25\% 25-50\% $50-75 \% 75-100 \%$

Did you have a job this summer? Yes/No

a. Was this a co-op placement? Yes/No

What is your overall undergraduate average?

How many times have you failed <this course> prior to this summer? (select one) never 12

How many times did you fail <prerequisite>? (select one) never 12 